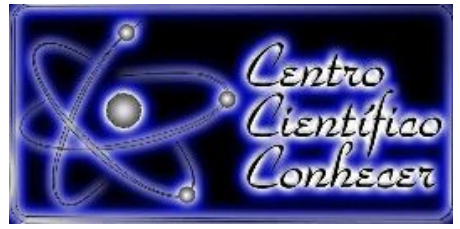

\title{
GERMINAÇÃO E VIGOR DE SEMENTES CRIOULAS DE FEIJÃO-CAUPI
}

\author{
José Tiago Barroso Chagas ${ }^{1}$, João Esdras Calaça Farias ${ }^{2}$, Rysley Fernandes de \\ Souza $^{2}$, Silvério de Paiva Freitas Júnior ${ }^{3}$ e Marília Gabriela de Santana Costa ${ }^{4}$ \\ ${ }^{1}$ Graduado em Agronomia pela Universidade Federal do Cariri (UFCA), Campus \\ Crato, Crato, CE, Brasil. \\ ${ }^{2}$ Graduando em Agronomia pela Universidade Federal do Cariri (UFCA), Campus \\ Crato, Crato, CE, Brasil. \\ ${ }^{3}$ Professor Adjunto no Centro de Ciências Agrárias e Biodiversidade da Universidade \\ Federal do Cariri (UFCA), Campus Crato, Crato, CE, Brasil. \\ ${ }^{4}$ Professora Doutora no Centro de Ciências Agrárias e Biodiversidade da \\ Universidade Federal do Cariri (UFCA), Campus Crato, Crato, CE, Brasil. \\ (mariliagabrielasc@hotmail.com).
}

\section{Recebido em: 14/07/2018 - Aprovado em: 28/07/2018 - Publicado em: 31/07/2018 DOI: 10.18677/Agrarian_Academy_2018a48}

\begin{abstract}
RESUMO
A qualidade fisiológica das sementes é um fator crucial no processo de produção, definindo o rendimento potencial dos cultivos. Tendo em vista a grande importância do feijão-caupi para a Região Nordeste do Brasil, bem como o fato das sementes crioulas serem mais comumente utilizadas pelos pequenos produtores, avaliou-se a viabilidade de sementes crioulas de cinco genótipos de feijão-caupi: Coruja; Rosinha; Sempre Verde; Cabeça de Gato; Paulistinha. As sementes foram adquiridas a partir de casas de sementes durante o ano de 2016 nas microrregiões da Chapada do Araripe, Barro, Cariri e Sertão de Senador Pompeu. As amostras foram submetidas aos testes de germinação, índice de velocidade de germinação e condutividade elétrica, além de determinações do percentual de umidade e peso de mil sementes. As análises mostraram diferenças de desempenho fisiológico entre os genótipos. Os acessos Rosinha e Cabeça de Gato tiveram desempenho superior no teste de germinação, sem diferença significativa entre os genótipos pelo teste de Scott-Knott $(p<0,01)$. O genótipo Rosinha ainda apresentou desempenho superior aos demais genótipos quanto a condutividade elétrica (68 $S \mathrm{~cm}-1 \mathrm{~g}-1)$ e a velocidade de germinação das sementes (17.25 in 24 hours). Neste contexto, a utilização de outros parâmetros é fundamental na diferenciação de genótipos que possuam o mesmo valor germinativo, mas que podem diferir em vigor.
\end{abstract}

PALAVRAS-CHAVE: germoplasma, qualidade fisiológica, Vigna unguiculata (L.) Walp 


\title{
GERMINATION AND VIGOR OF LANDRACE SEEDS OF COWPEA BEAN
}

\begin{abstract}
The seeds physiological quality has a key part to play in the agricultural production process, defining the crops yield potential. Due the great importance of cowpea bean to the Northeast region of Brazil, and the fact that landrace seeds are most frequently used by small farmers, the purpose of this study was to evaluate the viability of landrace seeds of following genotypes of cowpea bean: Coruja, Rosinha, Sempre Verde, Cabeça de Gato, and Paulistinha. The seeds were obtained from the microregions of Chapada do Araripe, Barro, Cariri and Sertão de Senador Pompeu, in the year 2016. The following tests were conducted: standard germination, speed germination, electrical conductivity, humidity and 1000-seed weight. The results showed that genotypes present different physiological performance. The germination of Rosinha and Cabeça de Gato genotypes were higher than other genotypes, and similar to each other, as evidenced by the Scott-Knott test $(p<0.01)$. The Rosinha genotype still presented electrical conductivity (68 $\mathrm{S} \mathrm{cm}^{-1} \mathrm{~g}^{-1}$ ) and speed germination (17.25 in 24 hours) higher than all other genotypes. In relation to humidity and 1000-seed weight the five genotypes presented similar responses. These results suggest would be valuable to use other parameters to differentiate genotypes, because they can present similar germination standard, but may differ in relation to vigor.
\end{abstract}

KEYWORDS: Vigna unguiculata (L.) Walp, germoplasm, physiological quality

\section{INTRODUÇÃO}

O feijão-caupi [Vigna unguiculata (L.) Walp] ocupa papel fundamental na nutrição de energia-proteína, ferro, zinco e minerais na alimentação humana, devido a sua importância para os povos de origem tropical e de regiões subtropicais, ambientes de alta instabilidade pluviométrica e baixo nível tecnológico (BEZERRA et al., 2014), o feijão-caupi tende a ser incrementado cada vez mais para produção de alto valor nutricional com rentabilidade. Além, de fornecer a estes povos segurança alimentar e nutricional, um dos principais obstáculos da humanidade para o desenvolvimento.

A região Nordeste do Brasil é a maior produtora de feijão-caupi, mesmo com variações negativas devido às perdas de safra provocadas pela estiagem, e representa mais de $50 \%$ da produção nacional do grão. No entanto, apresenta produtividade inferior à de outras regiões, como a centro-oeste, o que caracteriza um desafio a produção de feijão principalmente pela escassez hídrica que os estados da região semiárida enfrentam (CONAB, 2017). A irregularidade de chuvas pode afetar alguns dos estádios fenológicos mais críticos para a produção final, que são a germinação e a emergência de plântulas (DUTRA et al., 2012).

Dessa forma, a semente se torna o principal insumo nos sistemas de produção, e a sua qualidade fisiológica é o principal fator responsável pelo bom desenvolvimento inicial em campo, gerando boa safra e alta produtividade (NOGUEIRA et al., 2014). O potencial fisiológico da semente está relacionado com os atributos de germinação e o vigor. Além disso, a qualidade fisiológica das sementes pode influenciar na velocidade de germinação e emergência, e, consequentemente, interferir na uniformidade do estande final, levando a perdas de produtividade (PADUA et al., 2010). 
A obtenção da melhor safra passa pela escolha da semente e é determinada por aquela que detém os melhores atributos genéticos, fisiológicos e agronômicos adaptados à região de interesse. No entanto, nas regiões do semiárido brasileiro algumas cultivares não tem obtido desempenho satisfatório em função da irregularidade das chuvas (PERAZZO et al, 2013). Portanto, o que predomina nestas condições é a utilização de sementes crioulas, que são variedades tradicionais, selecionadas por agricultores de geração em geração, ao longo de várias décadas (SOARES JÚNIOR et al., 2015).

As sementes crioulas utilizadas na agricultura familiar nordestina advêm de diversas variedades e são importantes para os pequenos agricultores, pois representam a sua base alimentar e cultural, o que torna fundamental a manutenção da qualidade fisiológica das sementes durante o armazenamento nas casas de sementes (ANTONELLO et al., 2009). Tendo em vista a importância das sementes crioulas, o objetivo do presente trabalho foi avaliar a qualidade fisiológica, em termos de germinação e vigor, de sementes crioulas de feijão-caupi provenientes de cinco genótipos comumente utilizados do estado do Ceará, através dos testes de germinação, índice de velocidade de germinação e condutividade elétrica.

\section{MATERIAL E MÉTODOS}

O experimento foi conduzido no Laboratório de Biologia do Centro de Ciências Agrárias e da Biodiversidade (CCAB) da Universidade Federal do Cariri (UFCA), localizado no município de Crato, estado do Ceará. As sementes utilizadas foram coletadas em cinco municípios cearenses, totalizando cinco genótipos: (1) Coruja; (2) Rosinha; (3) Sempre Verde; (4) Cabeça de Gato; (5) Paulistinha, que foram coletados nos municípios de Potengi, Crato, Mombaça, Santana do Cariri e Mauriti, respectivamente.

As cultivares testadas foram selecionadas com base no potencial de adaptabilidade as condições edafoclimáticas e ambientais de quatro microrregiões do estado do Ceará: (1) Chapada do Araripe; (2) Barro; (3) Cariri; (4) Sertão de Senador Pompeu. As sementes foram obtidas durante a safra de 2016/2017 em casas de sementes e, ou através de agricultores familiares das microrregiões mencionadas.

A determinação da umidade foi realizada com quatro repetições de $10 \mathrm{~g}$ para cada genótipo por meio de método expedito (BRASIL, 2009). O equipamento utilizado foi um medidor de grãos portátil da marca Gehaka modelo G600, que foi calibrado segundo os genótipos avaliados.

$O$ peso de mil sementes foi determinado para cada genótipo segundo os procedimentos das Regras para Análise de Sementes (BRASIL, 2009). A partir da porção de sementes puras, separou-se ao acaso oito repetições de 100 sementes para cada um dos cinco genótipos e o peso de mil sementes (PMS) foi calculado pela seguinte fórmula: $\mathrm{PMS}=($ peso da amostra $\times 1000) /$ número total de sementes.

Para o teste de germinação foram selecionadas 50 sementes para cada genótipo estudado, estas foram semeadas em três folhas de papel do tipo Germitest em formato de rolo. O papel foi previamente umedecido com água destilada na proporção de 2,5 vezes o peso do substrato. As sementes foram dispostas respeitando uma distância de duas vezes seu tamanho e envoltas pelo papel formando um rolo. Em seguida os rolos foram colocados em posição vertical na câmara de germinação do tipo B.O.D (baixa demanda de oxigênio), sob ausência de 
luz e à temperatura constante de $25^{\circ} \mathrm{C}$ e envoltos por sacos plásticos. Após quatro dias foi realizada a contagem de plantas normais, anormais, e sementes mortas e a porcentagem de germinação foi determinada a partir do número de plântulas consideradas normais.

O índice de velocidade de germinação (IVG) foi realizado concomitantemente com o teste de germinação e determinado através da contagem de sementes germinadas às 24, 48, 72 e 96 horas a partir do momento em que as sementes foram submetidas as condições germinativas ideais, de temperatura e acondicionamento do teste de germinação, calculando a partir daí um índice em função do tempo e da quantidade de plântulas germinadas (BRASIL, 2009). Foram consideradas como germinadas as sementes com radícula de tamanho igual ou superior a 0,2 cm. O IVG foi calculado através do somatório do número de sementes germinadas a cada dia, dividido pelo número de dias decorridos entre a semeadura e a germinação, segundo a fórmula de Maguire (1962). IVG $=(G 1 / N 1)+(G 2 / N 2)+$ $(\mathrm{G} 3 / \mathrm{N} 3)+\ldots+(\mathrm{Gn} / \mathrm{Nn})$, em que: IVG = índice de velocidade de germinação, G1, G2, $\mathrm{G} 3, \ldots, \mathrm{Gn}=$ número de plântulas computadas na primeira, segunda, terceira e última contagem; N1, N2, N3, ..., Nn = número de dias da semeadura à primeira, segunda, terceira e última contagem.

Para o teste de condutividade elétrica foram utilizadas quatro repetições de 25 sementes, pesadas e dispostas em copos de plástico contendo $75 \mathrm{~mL}$ de água destilada. As sementes permaneceram embebidas por um período de 24 horas, à temperatura de $25^{\circ} \mathrm{C}$ acondicionadas em B.O.D. Após este período foi realizada a leitura da condutividade elétrica no condutivímetro da marca Oakton modelo CON 700 , os dados obtidos através do equipamento foram divididos pelo peso em gramas de cada amostra, sendo os resultados expressos em $\mu \mathrm{S} . \mathrm{cm}^{-1} \cdot \mathrm{g}^{-1}$.

As análises estatísticas foram realizadas pelo programa Assistat- versão 7.7 (SILVA; AZEVEDO, 2016), o delineamento experimental utilizado foi o inteiramente casualizado (DIC) com cinco tratamentos e quatro repetições e as diferenças significativas foram observadas através do teste de Scott-Knott à $1 \%$ de probabilidade.

\section{RESULTADOS E DISCUSSÃO}

Quanto ao teor de umidade das sementes observou-se que os genótipos apresentaram uma variação entre $9 \%$ a $11 \%$ (Tabela 1). No entanto, esses valores de umidade estão próximos ou na faixa da condição ideal de armazenamento, uma vez que a umidade precisa ser mantida de 11 a 13\% a fim de evitar a deterioração das sementes por respiração (BRAGANTINI, 2005). Esses dados sugerem que as diferenças no teor de umidade não influenciaram nos resultados dos testes realizados posteriormente.

Em relação ao peso de mil sementes, algumas diferenças entre os genótipos analisados foram observadas. O genótipo rosinha apresentou o menor valor de peso de mil sementes, com $168 \mathrm{~g}$, e o genótipo com maior peso de mil sementes foi o paulistinha, com 258g (Tabela 1). Desse modo, verifica-se um intervalo de quase $100 \mathrm{~g}$ de diferença entre os genótipos rosinha e paulistinha. Essa diferença observada pode ser determinada pela constituição genética das variedades, visto que o genótipo rosinha apresenta sementes de menor tamanho quando comparado com os demais genótipos estudados. 
TABELA 1 - Teor de umidade, peso de mil sementes e germinação de sementes crioulas dos cinco genótipos de feijão-caupi coletados no estado do Ceará.

\begin{tabular}{cccc}
\hline GENÓTIPO & Umidade (\%) & Peso de mil sementes (g) & Germinação (\%) \\
\hline Cabeça de Gato & 10,6 & 214,03 & 92 \\
Sempre Verde & 10,2 & 206,24 & 85 \\
Rosinha & 11 & 168,30 & 95 \\
Coruja & 9 & 240,55 & 87 \\
Paulistinha & 11,2 & 258,19 & 84,5 \\
\hline
\end{tabular}

O teste de germinação foi determinado em termos de porcentagem de plântulas normais das sementes relativas aos cinco genótipos estudados de acordo com as Regras para Análises de Sementes-RAS (BRASIL, 2009). Todos os genótipos apresentaram porcentagem de germinação acima de $80 \%$, que o valor mínimo comercial estabelecido pela RAS (BRASIL, 2009). A faixa de variação da porcentagem de germinação foi de 84,5 a $95 \%$, com os genótipos Paulistinha e Rosinha com a menor e maior taxa de germinação, respectivamente (Tabela 1).

Com o intuito de determinar se essas diferenças observadas e apontadas na tabela 1 são devido ao acaso, foi realizada a análise de variância dos dados de porcentagem de germinação. Em termos de porcentagem de plântulas normais e anormais foram encontradas diferenças significativas à $1 \%$ de probabilidade através do teste de Scott-Knott. Já para a porcentagem de sementes mortas não houve diferença significativa entre os genótipos (Tabela 2).

De acordo com os dados obtidos, os genótipos podem ser diferenciados em dois grupos distintos, e que diferem estatisticamente entre si. O primeiro grupo é composto pelos genótipos Cabeça de Gato e Rosinha, com média igual a 92 e 95\% de plântulas normais e 8 e $5 \%$ de plântulas anormais, respectivamente (Tabela 2). Esses genótipos apresentaram o melhor desempenho no teste de germinação, visto que obtiverem a maior porcentagem de plântulas normais e uma menor taxa de plântulas anormais. Compondo o segundo grupo, tem-se os genótipos Sempre Verde, Paulistinha e Coruja, com a média de porcentagem de plântulas normais variando de 84,5 a $87 \%$ e de plântulas anormais entre 13 e 15\% (Tabela 2). Para o genótipo paulistinha a porcentagem de germinação de 84,5 corrobora com o valor obtido no trabalho desenvolvido por Arruda et al. (2009) em que a germinação do genótipo denominado de paulistinha foi de $79,5 \%$. 
TABELA 2 - Médias de Plântulas normais (PN), anormais (PA) e sementes mortas (SM) por genótipo. Médias seguidas por letras diferentes na coluna diferem estatisticamente entre si; ${ }^{*}$ diferença significativa a $1 \%$ de probabilidade pelo teste de Scott-Knott; ${ }^{\text {ns }}$ não há diferença significativa; CV - Coeficiente de variação.

\begin{tabular}{cccc}
\hline GENÓTIPO & P.N. $^{* *}$ & P.A. $^{* *}$ & S.M. ${ }^{\text {ns }}$ ) \\
\hline Cabeça de gato & $92,00 \mathrm{a}$ & $8,00 \mathrm{~b}$ & $0,00 \mathrm{a}$ \\
Rosinha & $95,00 \mathrm{a}$ & $5,00 \mathrm{~b}$ & $0,00 \mathrm{a}$ \\
Sempre verde & $85,00 \mathrm{~b}$ & $14,50 \mathrm{a}$ & $0,50 \mathrm{a}$ \\
Paulistinha & $84,50 \mathrm{~b}$ & $15,00 \mathrm{a}$ & $0,50 \mathrm{a}$ \\
Coruja & $87,00 \mathrm{~b}$ & $13,00 \mathrm{a}$ & $0,00 \mathrm{a}$ \\
\hline MÉDIA & 88,70 & 11,10 & 0,20 \\
\hline CV(\%) & 3,76 & 30,77 & 316,23 \\
\hline
\end{tabular}

Vale salientar que os valores de porcentagem de germinação observados em laboratório são obtidos em condições ótimas para a germinação. Entretanto, no campo existem condições adversas que podem alterar esses valores comerciais de germinação. Devido a isso, apenas com o uso do teste de germinação não é possível distinguir lotes de sementes ou genótipos que possuem porcentagem de germinação similar, porém podem divergir quanto ao vigor. Por exemplo, Batista et al. (2012) não conseguiram identificar diferenças significativas entre genótipos avaliados quanto à porcentagem de germinação de quatro lotes de sementes da cultivar BRS Guariba.

Ademais, o coeficiente de variação igual a $3,76 \%$ para plântulas normais atesta a confiabilidade dos dados apresentados, uma vez que esse parâmetro é o principal componente na determinação da porcentagem de germinação. Outro trabalho avaliando a quantidade de plântulas anormais e sementes mortas mostrou valores de coeficiente de variação (CV) semelhantes aos encontrados no teste de germinação, com valores de 86,61 para plântulas anormais e 225,89 de sementes mortas, o que demonstra que esses altos valores de CV estão relacionados com a variável (GASPARIN et al., 2012).

O índice de velocidade de germinação (IVG) foi calculado conforme descrito na metodologia e a partir de avaliações realizadas em quatro intervalos de tempo (24, 48, 72 e 96 horas). Posteriormente, um gráfico de tendência foi elaborado a partir das médias do IVG para cada genótipo, com a finalidade de observar a dispersão desses índices em relação ao tempo de avaliação (Figura 1). Com isso, pode-se observar que a maioria dos genótipos estudados possue uma mesma tendência quanto a velocidade de germinação média em relação ao tempo, com exceção do genótipo Rosinha que demonstrou maior IVG médio nas primeiras $24 \mathrm{~h}$ do teste (Figura 1).

AGRARIAN ACADEMY, Centro Científico Conhecer - Goiânia, v.5, n.9; p. 4922018 


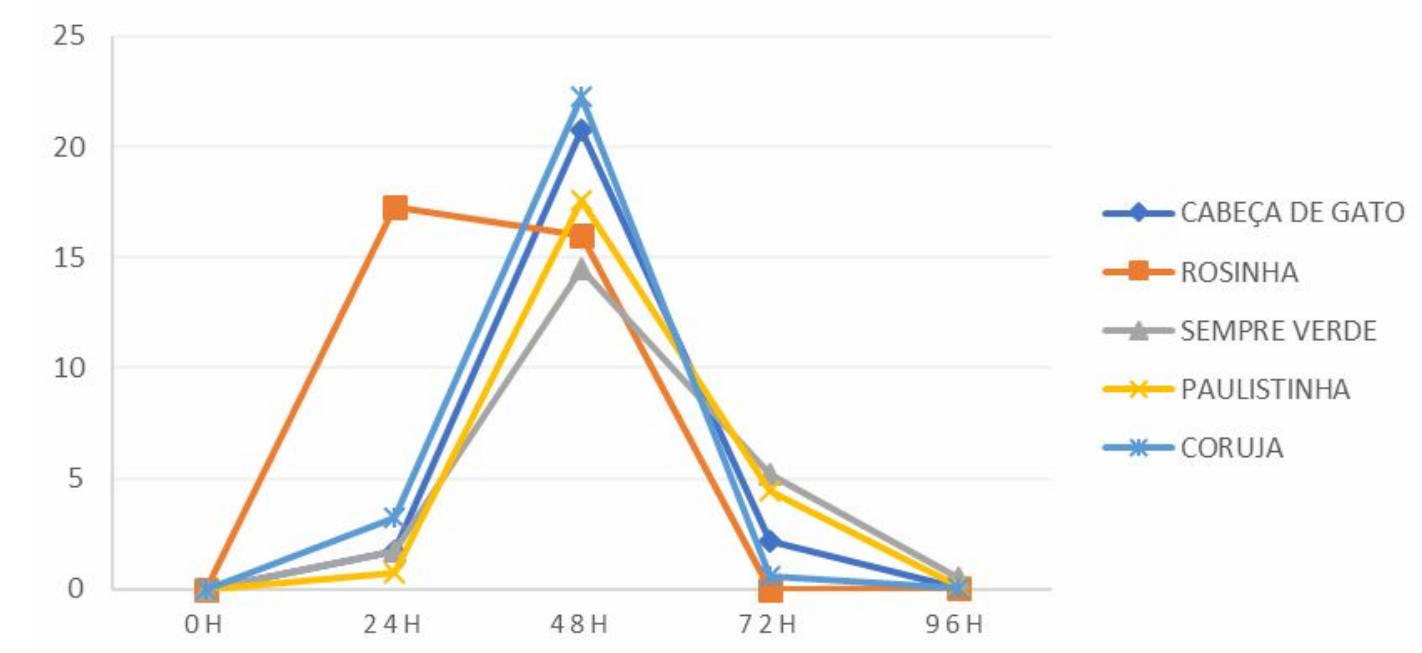

FIGURA 1 - Tendência média de velocidade de germinação das sementes de diferentes genótipos em relação aos dias de contagem.

Embora o genótipo Rosinha e Cabeça de Gato não tenham diferido estatisticamente em relação a percentagem de germinação, os dados de IVG demonstraram uma divergência de comportamento entre esses genótipos, que pode ser compreendida como diferença de vigor, já que há um diferencial na velocidade de germinação entre esses genótipos, ou seja, no tempo necessário para que cada genótipo expresse o seu máximo potencial germinativo. No entanto, estudos apontam que cultivares com porcentagem de germinação e emergência semelhantes, frequentemente possuem diferenças na velocidade de germinação e emergência (MARCARELLO et al., 2012).

Com o propósito de avaliar a significância dessas diferenças no IVG, foi realizada a análise de variância e o teste de média de Scott-Knott com nível de confiança de $99 \%$. A partir dos resultados do teste de média, diferenças significativas importantes foram observadas (Tabela 3). Na avaliação de $24 \mathrm{~h}$ o genótipo Rosinha apresentou um desempenho superior aos demais genótipos estudados, com uma média de IVG aproximadamente seis vezes maior que a segunda maior média, enquanto que entre os outros genótipos não foram observadas diferenças significativas (Tabela 3 ).

$\mathrm{Na}$ avaliação de 48h os genótipos Cabeça de Gato e Coruja mostraram uma maior média de IVG (Tabela 3). Embora o genótipo Rosinha não tenha diferido estatisticamente dos demais na avaliação as $48 \mathrm{~h}$, nota-se que a maior parte das sementes desse genótipo já haviam germinado (98\%). As causas dessas respostas podem residir na constituição genética da variedade Rosinha, visto que as demais condições experimentais foram mantidas sobre estabilidade de temperatura, água, luz e demanda bioquímica de oxigênio. Os genótipos: Sempre Verde e Paulistinha demonstraram menor velocidade de germinação, melhor distribuída no tempo em relação aos demais genótipos, apresentando um IVG maior em relação aos outros genótipos apenas as $72 \mathrm{~h}$, momento em que os demais genótipos apresentavam percentual próximo a 100\% de germinação (Tabela 3). 
TABELA 3 - Médias das sementes dos genótipos Cabeça de Gato, Rosinha, Sempre Verde, Paulistinha e Coruja na velocidade de germinação de 24, 48, 72 e 96h. Médias seguidas por letras diferentes na coluna diferem entre si pelo teste de Scott-Knott a 1\% de probabilidade; CV - Coeficiente de variação.

\begin{tabular}{ccccc}
\hline GENÓTIPO & $\mathbf{2 4 h}$ & $\mathbf{4 8 h}$ & $\mathbf{7 2 h}$ & $\mathbf{9 6 h}$ \\
\hline Cabeça de gato & $1,75 \mathrm{~b}$ & $20,75 \mathrm{a}$ & $2,15 \mathrm{~b}$ & $0,075 \mathrm{~b}$ \\
Rosinha & $17,25 \mathrm{a}$ & $16,00 \mathrm{~b}$ & $0,00 \mathrm{~b}$ & $0,075 \mathrm{~b}$ \\
Sempre verde & $1,75 \mathrm{~b}$ & $14,50 \mathrm{~b}$ & $5,175 \mathrm{a}$ & $0,525 \mathrm{a}$ \\
Paulistinha & $0,75 \mathrm{~b}$ & $17,625 \mathrm{~b}$ & $4,40 \mathrm{a}$ & $0,15 \mathrm{~b}$ \\
Coruja & $3,25 \mathrm{~b}$ & $22,25 \mathrm{a}$ & $0,60 \mathrm{~b}$ & $0,075 \mathrm{~b}$ \\
\hline MÉDIA & 4,95 & 18,225 & 2,465 & 0,18 \\
\hline CV (\%) & 61,22 & 25,01 & 66,00 & 137,59 \\
\hline
\end{tabular}

Os resultados encontrados apontam que existem diferenças de vigor entre os genótipos em termos de maior ou menor velocidade de germinação. Resultados similares foram obtidos por Silva et al., (2014) que conseguiram diferenciar oito genótipos de feijão-caupi através do índice de velocidade de emergência, separando de forma eficiente as sementes pelo vigor. O maior IVG do genótipo Rosinha pode ser relacionado com o fato do genótipo possuir sementes de menor tamanho. Outros autores observaram que sementes menores de feijão-caupi da cultivar Nova era da Embrapa Meio-Norte possuíam maior velocidade de germinação, e, a explicação para esse desempenho diferencial reside no fato de que sementes menores necessitaram de menor quantidade de água para serem embebidas e germinar (ARAÚJO NETO et al., 2014).

Para obter maior consistência na distinção dos genótipos quanto ao vigor, optou-se por realizar o teste de condutividade elétrica. Este teste relaciona a capacidade de reorganização e reparo da integridade de membranas durante o processo de embebição das sementes, quanto maior a eficiência no restabelecimento da integridade da membrana celular, menos eletrólitos são liberados na solução e maior é o vigor das sementes. Matos et al. (2015) confirmam que durante o teste de condutividade elétrica, à medida em que a viabilidade das sementes diminui há um aumento na liberação de exsudados das sementes, pela água que permeiam as membranas celulares sinalizando a perda da integridade destas membranas.

A partir dos dados obtidos, foi possível observar a configuração de 3 grupos. O primeiro grupo, composto pelos genótipos Paulistinha e Coruja, obteve as maiores médias com 123,5 e 109,2 $\mu \mathrm{S} . \mathrm{cm}^{-1} \cdot \mathrm{g}^{-1}$, de modo respectivo. $\mathrm{O}$ segundo grupo, AGRARIAN ACADEMY, Centro Científico Conhecer - Goiânia, v.5, n.9; p. 4942018 
manteve-se com valores intermediários, composto pelos genótipos Cabeça de Gato e Sempre Verde, com média de 96,6 e $88,8 \mu \mathrm{S} . \mathrm{cm}^{-1} \cdot \mathrm{g}^{-1}$, respectivamente. Por último, o grupo composto apenas pelo genótipo Rosinha, com média igual a $68 \mu \mathrm{S} . \mathrm{cm}^{-1} \cdot \mathrm{g}^{-1}$ apresentando uma menor liberação de eletrólitos (Tabela 4).

TABELA 4 - Médias de condutividade elétrica das sementes dos genótipos Cabeça de Gato, Sempre Verde, Coruja, Rosinha, Paulistinha. Médias seguidas por letras diferentes na coluna diferem entre si pelo teste de Scott-Knott a 1\% de probabilidade; CV - Coeficiente de variação.

TRATAMENTOS

Cabeça de Gato

Sempre Verde

Coruja

Rosinha

Paulistinha
MÉDIAS $\left(\mu S . \mathrm{cm}^{-1} \cdot \mathrm{g}^{-1}\right)$

$96,675 b$

$88,875 \mathrm{~b}$

109,225 a

$68,075 \mathrm{c}$

123,25 a
MÉDIA

$\mathrm{CV}(\%)$
97,23

10,32

Diante disso, o genótipo Rosinha se destacou dos demais por obter o menor valor de condutividade elétrica e consequentemente apresentar a melhor reposta de vigor fisiológico dentre os genótipos avaliados. Moura et al. (2016) afirmam que quanto menor os valores da condutividade elétrica, maior a resposta fisiológica das sementes. Com isso, os dados de condutividade, confirmam os resultados obtidos na avaliação do IVG, em que o genótipo em questão demonstrou um desempenho superior em relação aos demais.

Baseado nos dados de IVG e condutividade elétrica é possível distinguir os genótipos estudados quanto ao vigor, o que não seria possível apenas através do teste de germinação. Assim como no presente trabalho, o teste de germinação nem sempre consegue diferenciar genótipos com base no vigor, sendo necessários testes adicionais como o teste de condutividade elétrica, IVG, teste de frio, envelhecimento acelerado, entre outros. Semelhantemente, Rodrigues et al. (2015) encontraram valores próximos para porcentagem de germinação das cultivares BRS Guariba, BRS Maratoã e BRS Pujante, porém somente através do teste de condutividade elétrica e índice de velocidade de emergência de plântulas foi possível indicar a cultivar "Pujante" como a de melhor potencial fisiológico. Conclusão semelhante é concebida por Batista et al. (2012) que ao avaliarem quatro lotes de sementes da cultivar BRS Guariba concluíram que o teste de condutividade elétrica é eficaz para selecionar lotes de sementes de feijão-caupi com base no potencial fisiológico. 


\section{CONCLUSÕES}

Com base nos testes realizados é possível afirmar que o teste de germinação não é eficiente para distinguir genótipos de potencial germinativo similar e que diferem quanto ao vigor.

As avaliações de IVG e condutividade elétrica foram eficientes em distinguir, quanto ao vigor, sementes que apresentam alto poder germinativo. Com isso, para distinção mais eficiente entre genótipos e ou lotes de sementes é necessário realizar outros testes além do teste padrão de germinação.

Dentre os genótipos crioulos avaliados, "rosinha" demonstrou uma qualidade fisiológica de sementes superior aos demais, no que concerne aos parâmetros de germinação e vigor.

\section{REFERÊNCIAS}

ANTONELLO, L. M.; MUNIZ, M. F. B.; BRAND, S. C.; RODRIGUES, J.; MENEZES, N. L.; KULCZYNSKI, S. M. Influência do tipo de embalagem na qualidade fisiológica de sementes de milho crioulo. Revista Brasileira de Sementes. [S.I.], vol. 31, n. 4, p. 75-86, ago., 2009. Disponível em: <http://dx.doi.org/10.1590/S010131222009000400009>. doi: 10.1590/S0101-31222009000400009.

ARAÚJO NETO, A. C.; NUNES, R. T. C.; ROCHA, P. A.; ÁVILA, J. S.; MORAIS, O. M. Germinação e vigor de sementes de feijão-caupi (Vigna unguiculta (L.) Walp.) de diferentes tamanhos. Revista Verde de Agroecologia e Desenvolvimento Sustentável, Mossoró, v. 9, n. 2, p. 71-75, 2014. Disponível em: <http://www.gvaa.com.br/revista/index.php/RVADS/article/view/2216>.

BATISTA, N. A. S.; LUZ, P. B.; SOBRINHO, S. P.; NEVES, L. G.; KRAUSE, W. Avaliação da qualidade fisiológica de sementes de feijão-caupi pelo teste de condutividade elétrica. Revista Ceres, Viçosa, v. 59, p. 550-554, jul./ago., 2012. Disponível em: <http://www.ceres.ufv.br/ojs/index.php/ceres/article/view/3889>.

BEZERRA, A. A. C.; NEVES, A. C.; ALCÂNTARA NETO, F.; SILVA JÚNIOR, J. V. Morfofisiologia e produção de feijão-caupi, cultivar BRS nova era, em função da densidade de plantas. Revista Caatinga, Mossoró, v. 27, n. 4, p. 135-141, out./dez., 2014. Disponível em: <http://www.redalyc.org/html/2371/237132753017/>.

BRAGANTINI, C. Alguns aspectos do armazenamento de sementes e grãos de Feijão. Santo Antônio de Goiás, GO. Embrapa Arroz e Feijão, 2005.

BRASIL. Ministério da Agricultura, Pecuária e Abastecimento. Regras para análise de sementes. Secretaria de Defesa Agropecuária. Brasília, DF, Mapa/ACS, 2009.

COMPANHIA NACIONAL DE ABASTECIMENTO. Acompanhamento da safra brasileira de grãos, v.5. Safra 2017/18. Primeiro Levantamento Outubro de 2017, Brasília, DF, 2017. Disponível em: <http://www.conab.gov.br/OlalaCMS/uploads/arquivos/17_10_16_16_34_39_graos_ outubro_2017.pdf>. Acesso em : 21 nov. 2017.

DUTRA, A. S.; BEZERRA, F. T. C.; NASCIMENTO, P. R.; LIMA, D. C. Produtividade e qualidade fisiológica de sementes de feijão caupi em função da adubação 
nitrogenada. Revista Ciência Agronômica, v. 43, p. 816-821. out./dez., 2012. Disponível em: < http://www.redalyc.org/html/1953/195323720025/>.

GASPARIN, E.; ARAUJO, M. M.; AVILA, A. L.; WIELEWICKI, A. P. Identificação de substrato adequado para germinação de sementes de allophylus (A. st.-Hil., A. Juss. \& Cambess.) Radlk. Revista Ciência Florestal, Santa Maria, v. 22, n. 3, p. 625-630, jul./set., 2012. Disponível em: <http://dx.doi.org/10.5902/198050986628>. doi: 10.5902/198050986628.

MAGUIRE, J. D. Speed of germination aid in selection and evaluation for seedling emergence and vigor. Crop Science, v.2, n.1, p.176-177. 1962. Disponível em: < https://dl.sciencesocieties.org/publications/cs/abstracts/2/2/CS0020020176>.

MARCARELLO, A.; YAMASHITA, O. M.; CARVALHO, M. A. C. Qualidade fisiológica de sementes de feijoeiro em função da aplicação foliar de cobalto e molibdênio. Global Science Technology, v. 5, n. 2, p. 121-132, 2012. Disponível em: < http://rv.ifgoiano.edu.br/periodicos/index.php/gst/article/view/494>.

MATOS, A. C. B.; BORGES, E. E. L.; SILVA, L. J. Fisiologia da germinação de sementes de Dalbergia nigra (Vell.) Allemão ex Benth. sob diferentes temperaturas e tempos de exposição. Revista Árvore, v. 39, n. 1, p. 115-125, 2015. Disponível em: <http://dx.doi.org/10.1590/0100-67622015000100011>. doi: 10.1590/010067622015000100011

MOURA, M. L. S.; CHAGAS, E. A.; SMIRDELE, O. J.; VILAÇA, R.; CHAGAS, P. C.; MOURA, E. A.; FARIAS, E. E. Biometric characterization water absorption curve and vigor on araça-boi seeds. International Journal of Plant Biology, v.7, n. 6265, 2016. Disponível em: < https://doi.org/10.4081/pb.2016.6265>. doi: $10.4081 / p b .2016 .6265$

NOGUEIRA, N. W.; FREITAS, R. M. O.; TORRES, S. B.; LEAL, C. C. P. Physiological maturation of cowpea seeds. Journal of Seed Science, [S.I.], v. 36, n. 3, p. 312-317, set., 2014. Disponível em: <http://dx.doi.org/10.1590/23171545v36n31007>. doi: 10.1590/2317-1545v36n31007

PÁDUA, G. P. de; ZITO, R. K.; ARANTES, N. E.; „RANÇA NETO, J. de B. Influência do tamanho da semente na qualidade fisiológica e na produtividade da cultura da soja. Revista Brasileira de Sementes, Pelotas, v. 32, n. 3, p. 09-16, 2010. Disponível em: < http://www.scielo.br/pdf/rbs/v32n3/v32n3a01>.

PERAZO, A. F.; SANTOS, E. M.; PINHO, R. M. A.; CAMPOS, F. S.; RAMOS, J. P. F.; AQUINO, M. M.; SILVA, T. C.; BEZERRA, H. F. C. Características agronômicas e eficiência do uso da chuva em cultivares de sorgo no semiárido. Revista Ciência Rural, Santa Maria, v. 43, n. 10, p. 1171-1176, out., 2013. Disponível em: <http://www.redalyc.org/html/331/33128114007/>.

RODRIGUES, A. P. M. S.; MENDONÇA JÚNIOR, A. F.; TORRES, S. B.; NOGUEIRA, N. W.; FREITAS, R. M. O. Teste de tetrazólio para avaliação da qualidade fisiológica de sementes de Vigna unguiculata (L.) Walp. Revista Ciência Agrônomica, v. 46, n. 3, p. 638-633, jul./set., 2015. Disponível em: < http://dx.doi.org/10.5935/18066690.20150048>. doi: 10.5935/1806-6690.20150048 
SILVA, A. C.; MORAIS, O. M.; SANTOS, J. L.; D'ARÊDE, L. O.; BENTO SILVA, P. Componentes de produção, produtividade e qualidade de sementes de feijão-caupi em Vitória da Conquista, Bahia. Revista Agro@mbiente On-Line, v. 8, p. 327-335, set./dez., 2014.

Disponível em:

https://revista.ufrr.br/agroambiente/article/view/1894>.

SILVA, F.A.S.; AZEVEDO, C.A.V. (2016). The Assistat Software Version 7.7 and its use in the analysis of experimental data. African Journal of Agricultural Research, v. 11(39), pp. 3733-3740, 29 September. DOI: 10.5897/AJAR2016.11522

SOARES JÚNIOR, M. S.; CALIARI, M.; BECKER, F. S.; SOUZA, E. R. B.; VERA, R. Propriedades físicas e químicas de grãos de feijões crioulos vermelhos. Revista Caatinga, Mossoró, v. 28, n. 1, p. 263-269, jan./mar., 2015. Disponível em: < http://www.redalyc.org/html/2371/237138297029/>. 